Christopher A. Whatley, Scottish Society 1707-1830. Beyond Jacobitism, Towards Industrialisation, Manchester: Manchester University Press, 2000

\title{
Christian Civardi
}

\section{(2) OpenEdition}

1 Journals

Édition électronique

URL : http://journals.openedition.org/rfcb/717

DOI : $10.4000 / \mathrm{rfcb} .717$

ISSN : 2429-4373

Éditeur

CRECIB - Centre de recherche et d'études en civilisation britannique

Édition imprimée

Date de publication : 1 février 2002

Pagination : 103

ISBN : 2-911580-13-3

ISSN : 0248-9015

Référence électronique

Christian Civardi, «Christopher A. Whatley, Scottish Society 1707-1830. Beyond Jacobitism, Towards Industrialisation, Manchester: Manchester University Press, 2000 », Revue Française de Civilisation Britannique [En ligne], XI-3 | 2002, mis en ligne le 21 mars 2016, consulté le 24 septembre 2020. URL http://journals.openedition.org/rfcb/717 ; DOI : https://doi.org/10.4000/rfcb.717

Ce document a été généré automatiquement le 24 septembre 2020.

Revue française de civilisation britannique est mis à disposition selon les termes de la licence Creative Commons Attribution - Pas d'Utilisation Commerciale - Pas de Modification 4.0 International. 


\title{
Christopher A. Whatley, Scottish Society 1707-1830. Beyond Jacobitism, Towards Industrialisation, Manchester: Manchester University Press, 2000
}

\author{
Christian Civardi
}

\section{RÉFÉRENCE}

Christopher A. Whatley, Scottish Society 1707-1830. Beyond Jacobitism, Towards Industrialisation, Manchester: Manchester University Press, 2000, 354p. Pbk : $€ 14.99$. ISBN 0-7190-4541-x. Hbk : $€$ 45. ISBN 0-7190-4540-1.

1 Depuis une trentaine d'années, grâce à une génération de chercheurs qui a dépouillé et interprété une masse considérable d'archives restées inexploitées, l'historiographie de l'Écosse s'est considérablement renouvelée. Le livre de Christopher Whatley tire le meilleur profit de cette mise à jour, à laquelle ses nombreux articles ont grandement contribué, pour présenter une histoire du peuple écossais dans cette période charnière qui, à partir du traité d'Union avec l'Angleterre, est marquée par une série de bouleversements politiques (échec des rébellions jacobites), religieux et culturels (hégémonie de la faction modérée de l'Église d'Écosse et des philosophes des Lumières écossaises), économiques (commercialisation de l'agriculture, première révolution industrielle) et sociaux (débuts de l'émigration massive des petits tenanciers des Hautes-Terres et de l'urbanisation des Basses-Terres et, à en croire l'auteur, échec des premières tentatives de constitution d'une classe ouvrière écossaise).

2 Christopher Whatley pose deux questions majeures : comment expliquer le décollage économique du milieu du XVIII ${ }^{\mathrm{e}}$ siècle ? Comment expliquer la relative paix sociale qui 
semble l'avoir accompagné? Ses réponses diffèrent de celles de la majorité des historiens contemporains. Rompant avec une longue tradition historiographique qui voyait dans I'Union parlementaire de 1707 la seule et unique cause des progrès économiques et intellectuels d'une Écosse tirée de son obscurantisme grâce à l'influence civilisatrice de l'Angleterre, les historiens de la nouvelle génération insistent sur les facteurs indigènes de modernisation de l'Église, des universités, du commerce, de l'agriculture et de l'industrie. Sans nier l'importance de ces éléments structurels, Whatley démontre que, sans l'Union, ils n'auraient pas suffi à redresser la courbe déclinante de la dernière décennie du XVII ${ }^{e}$ siècle, marquée par la dégradation des sols, le très coûteux échec de la tentative de colonisation de l'isthme de Darien et des conditions climatiques catastrophiques. Sur ces points, Whatley rejoint les positions de Christopher Smout (A History of the Scottish People, 1560-1830, 1969), dénoncées par les historiens qui, insistant sur les facteurs indigènes du développement, se qualifient (reprenant la terminologie de Franz Fanon) d' "anti-inférioristes ». Ainsi, Whatley montre de façon convaincante que la faiblesse de la marine écossaise, tant marchande que militaire, obérait les exportations de lin, de charbon et de bovins, à tel point qu'au moment de l'Union, l'économie de l'Écosse était en plus mauvais point que celle de sa voisine irlandaise.

3 L'étude des conséquences économiques de l'Union est détaillée et nuancée. Se fondant sur des sources contemporaines, en particulier les rapports d'un espion industriel suédois, Whatley montre que, contrairement à une idée reçue, les premiers à profiter du nouveau marché américain ne furent pas les négociants en tabac de Glasgow, mais les producteurs et les négociants de céréales. Il prend de nouveau ses distances par rapport aux "anti-inférioristes" en mettant l'accent sur le rôle moteur de l'État britannique - soucieux d'éviter tout mécontentement populaire qui pourrait être récupéré par les jacobites - dans le décollage économique du pays : fondation par loi parlementaire, en 1727, du Board of Trustees for Fisheries and Manufactures et de la Royal Bank of Scotland ; protection d une puissante Royal Navy ; protectionnisme favorable aux exportations de sel et de lin écossais ; mais aussi capacité de l'État à fermer les yeux sur la contrebande de tabac non déclaré entre la Virginie et Glasgow. Fondée sur de multiples sources, l'étude de la spécialisation régionale qu'induit la révolution agricole est particulièrement novatrice, ainsi que celle consacrée à l'importance de la maind'œuvre féminine dans l'agriculture, puis dans l'industrie textile : au début du XIX ${ }^{\mathrm{e}}$ siècle, les deux-tiers des travailleurs de l'industrie manufacturière écossaise étaient des femmes ou des enfants.

4 Moins originale en revanche est la question que pose l'auteur dans la deuxième partie de son livre, sur la relative passivité, voire l'équanimité, avec laquelle le peuple aurait accepté les bouleversements induits par l'Union, puis par les révolutions agricole et industrielle. Comme Whatley le rappelle, il y a déjà en partie répondu dans un article de 1992 ("An uninflammable people ?" in Donnachie \& Whatley (eds.), The Manufacture of Scottish History). Manifestement, la parution entre-temps de plusieurs ouvrages partisans de la théorie de la stabilité (et/ou de la rébellion "feu de paille ») l'a incité à remettre son ouvrage sur le métier, et à étayer plus solidement encore sa réponse. Le recours à une masse impressionnante de sources originales- journaux et correspondances privés, mémorandums, rapports d'intendants, délibérations de conseils municipaux, pétitions d'employeurs à destination des sheriffs, etc., tant dans les Highlands que dans les Lowlands - lui a permis de mettre en évidence l'existence d'un nombre d'émeutes bien plus important qu'on l'estimait jusqu'à présent, notamment de 
deux types, les "émeutes de la faim» (food riots) et les émeutes "anti-gabelous" (customs and excise riots), ainsi que le recours généralisé à la troupe pour les mater. Son étude de la Radical War de 1820, insurrection ouvrière de l'Ouest de l'Écosse rapidement étouffée, dont trois des meneurs furent exécutés, montre de façon convaincante que, loin d'être un simple feu de paille, cette insurrection contribua de façon décisive à la prise de conscience d'une communauté d'intérêts et de destin parmi les ouvriers de la région, qu'ils soient tisserands, mineurs ou fondeurs. Forgée en 1820, leur alliance renaîtra une quinzaine d'années plus tard sous la forme du chartisme écossais.

5 À plusieurs reprises dans son ouvrage, Christopher whatley laisse entendre qu'il s'est fixé comme ambition de faire pour la classe ouvrière écossaise ce que E. P. Thompson a accompli pour l'anglaise dans son The Making of the English Working Class (1963). Il y parvient, à une remarque près toutefois : s'il met bien (comme Thompson) en évidence la fonction de régulation sociale de l'Église, Whatley sous-estime la contribution de l'école (dont on sait qu'elle était bien plus accessible qu'en Angleterre) à l'ouverture des esprits, n'y consacrant qu'une seule page. Reproche bien mineur toutefois au regard de l'apport considérable que représente cette history from below appelée à faire date dans l'historiographie de l'Écosse.

\section{AUTEURS}

\section{CHRISTIAN CIVARDI}

Université Strasbourg II 